\title{
Critical review and synthesis of the epidemiologic evidence on formaldehyde exposure and risk of leukemia and other lymphohematopoietic malignancies
}

\author{
Harvey Checkoway $\cdot$ Paolo Boffetta $\cdot$ \\ Diane J. Mundt $\cdot$ Kenneth A. Mundt
}

Received: 4 April 2012/ Accepted: 14 August 2012/Published online: 15 September 2012

(C) The Author(s) 2012. This article is published with open access at Springerlink.com

\begin{abstract}
Purpose Recent epidemiologic studies indicate elevated risks for some lymphohematopoietic malignancies (LHM) related to formaldehyde exposure. We performed a systematic review of literature to assess the strength and consistency of associations.

Methods We summarized published literature in the PubMed database of the National Library of Medicine during 1966-2012. Literature was categorized according to study design and population: industrial cohort studies, professional cohort studies, and population-based casecontrol studies.

Results Findings from occupational cohort and population-based case-control studies were very inconsistent for LHM, including myeloid leukemia. Apart from some isolated exceptions, relative risks were close to the null, and there was little evidence for dose-response relations for any of the LHM.

Conclusions At present, there is no consistent or strong epidemiologic evidence that formaldehyde is causally related to any of the LHM. The absence of established
\end{abstract}

\section{H. Checkoway ( $\square)$}

Department of Environmental Health, School of Public Health and Medicine, University of Washington, Box 357234, Seattle, WA 98195, USA

e-mail: checko@u.washington.edu

\section{P. Boffetta}

Mt. Sinai School of Medicine, Institute for Translational

Epidemiology, New York, NY 10029, USA

\section{J. Mundt}

ENVIRON International Corporation, Boston, MA 02110, USA

K. A. Mundt

ENVIRON International Corporation, Amherst, MA 01002, USA toxicological mechanisms further weakens any arguments for causation. To be informative, future epidemiologic research should improve on formaldehyde exposure assessment and apply modern diagnostic schemes for specific LHM.

Keywords Formaldehyde - Leukemia - Lymphoma . Lymphohematopoietic malignancies - Epidemiologic review $\cdot$ Causation

\section{Introduction}

Formaldehyde $\left(\mathrm{CH}_{2} \mathrm{O}\right)$ is a simple one-carbon molecule, found in most human and other living cells as a normal product of the metabolism of serine, glycine, methionine, and choline, and is generated in the demethylation of $\mathrm{N}-, \mathrm{O}-$, and S-methyl compounds. It is also an essential intermediate in the biosynthesis of purines, thymidine, and various amino acids [1]. Consequently, formaldehyde is present in virtually all cells in the body at varying concentrations.

Formaldehyde is also produced commercially and is valuable as a biocide, preservative, and basic chemical in the manufacture of common materials such as plastics, building materials, glues and fabrics, and many household and consumer products, including medicines, health, and beauty aids. Formaldehyde is also a product of organic matter combustion.

Common exposure sources include some laboratories, indoor air (e.g., carpets), vehicle emissions, cigarette smoke, and workplaces manufacturing or using resins, various wood products (e.g., particle board), adhesives, textiles, and numerous other consumer products [2]. High concentrations of formaldehyde were found inside some of the temporary housing units built for victims of hurricane Katrina in the US in 2008, which raised the public awareness of the chemical and its potential acute health effects $[3,4]$. 
Inhalation is the predominant route of exposure to exogenous formaldehyde. Following inhalation, formaldehyde rapidly reaches cells in the upper respiratory tract and reacts virtually instantaneously with primary and secondary amines, thiols, hydroxyls, and amides [5]. Formaldehyde is swiftly metabolized by erythrocytes [6-9]. Formaldehyde forms adducts with DNA and proteins and also produces DNA cross-links [10].

The most common acute health effects of exposure to formaldehyde include eye and upper respiratory tract irritation. Reversible declines in lung function have also been observed, although the evidence that it causes asthma and other chronic respiratory diseases is inconsistent [11]. There is inadequate evidence to assess other potential adverse effects of formaldehyde in humans, such as immunotoxicity, neurotoxicity, and reproductive and developmental toxicity $[12,13]$.

\section{Carcinogenicity of formaldehyde}

Concerns about the carcinogenicity of formaldehyde were prompted in the early 1980 s by the induction of nasal tumors in rats exposed at high concentrations [14-17]. As a consequence, the focus of early epidemiologic studies was on nasal cancer, based on the understanding that formaldehyde is rapidly metabolized at the site of contact (i.e., nasal passages and cavity) [18-20]. Consequently, associations between formaldehyde exposure and other malignancies in humans were reported, including nasopharyngeal carcinoma (NPC), lung cancer, lymphohematopoietic malignancies (LHM), mainly leukemias, and other cancers such as brain, colon, and prostate [21, 22]. Epidemiologic studies on formaldehyde exposure and LHM risk are reviewed in detail below.

In 2006, the International Agency for Research on Cancer (IARC) conducted a comprehensive review of the literature and classified formaldehyde as a known (i.e., Group 1) human carcinogen, based on sufficient evidence for NPC. The evidence for leukemia was considered suggestive [23]. In 2009, IARC conducted an abbreviated updated review of all Group 1 chemicals, including formaldehyde [24], in which the epidemiologic evidence for leukemia_-specifically myeloid leukemias_was classified as sufficient. The US National Toxicology Program similarly classified formaldehyde as a known human carcinogen [25]. The US Environmental Protection Agency (EPA), in its draft Integrated Risk Information System (IRIS) report on formaldehyde, concluded that existing epidemiologic evidence supported a causal association with LHM as a group and specifically for myeloid leukemia [26]. A special committee of the US National Research Council of the National Academies critically reviewed the EPA draft
IRIS report and found the causal conclusions for LHM to be inadequately supported [27].

We undertook a critical, systematic, and comprehensive review and synthesis of the epidemiologic literature on formaldehyde and risks of the LHM. Our review is more thorough than that produced by the National Research Council [27], which focused on literature summarized in the EPA draft IRIS document. Our objectives were to characterize the overall strength and consistency of the evidence to guide causal interpretations and to recommend research improvements that would extend knowledge on this important public health and scientific issue.

\section{Methods}

Our methods were consistent with those used by IARC [28] and others [29-31]. Briefly, we identified published, peerreviewed epidemiologic studies specifically addressing formaldehyde exposure and risk of the LHM. Searches were conducted in PubMed, the US National Library of Medicine's primary research tool that indexes most of the world's health and medical peer-reviewed journals since at least 1966. All years indexed were searched to identify these studies using the following key words in various combinations: cancer, leukemia, non-Hodgkin's lymphoma, lymphoma, lymphocytic, Hodgkin's lymphoma, hematopoietic, multiple myeloma, hematological neoplasm, formaldehyde, embalmer, garment, laboratory workers, epidemiology, case-control, cohort, case-referent, occupational, chemical, exposure, risk, review, meta-analysis, and commentary. We identified a total of 1,441 potentially relevant articles from the literature searches. Of these articles, 126 were retained as relevant to formaldehyde exposures and LHM. Articles were excluded if they (1) were not epidemiological studies, (2) did not focus on formaldehyde, (3) focused on outcomes other than cancer, or (4) did not present results for specifically for LHM. Additionally, references cited in other publications, including reviews, were checked to ensure the thoroughness of the literature review. We did not attempt to identify unpublished reports. The final review included a total of 37 articles-22 cohort studies and 17 case-control studies.

We comprehensively reviewed the identified literature, including studies of occupational groups and populationbased case-control studies of specific LHM that presented results for formaldehyde-related exposures. Most emphasis was placed on findings from occupational cohort studies, which, because of the greater potential for exposure to substantial concentrations of formaldehyde, provide the best evidence for possible associations. We limited the review to the most recent updates of occupational studies, although we include findings from earlier reports where results have changed materially with successive updates. 
Defining the outcome of interest is an important aspect of the design of epidemiologic studies, and the LHM are particularly challenging in this regard. Much of the information about LHM and formaldehyde exposure derives from mortality data in occupational cohort studies that spanned several LHM classification schemes. The principles of the nosological classification of this group of neoplasms have changed during the past 40 years, following the increasing understanding of the pathological and clinical characteristics of the different diseases. The most substantial changes in the International Classification of Diseases (ICD) have occurred for the non-Hodgkin lymphomas (NHL). Until the 9th Revision of the International Classification of Diseases (ICD), NHL was classified under two rubrics: "lymphosarcoma and reticulosarcoma" and "other neoplasms of the lymphoid tissue" (Hodgkin lymphoma had a separate code) [32]. In ICD-10, which follows a new WHO classification, chronic lymphocytic leukemia (CLL), the most common type of leukemia among the elderly, is classified as a form of NHL, and other changes were made to the classification of NHL. The InterLymph Consortium of lymphoma epidemiology has made an effort to adapt the last two versions of the WHO classification to epidemiologic studies, following a hierarchical approach $[33,34]$. Unfortunately, the majority of epidemiologic studies, in particular occupational cohort studies, which based outcomes on death certificates, do not follow the WHO classifications (or its InterLymph adaptation).

We present and discuss findings for specific LHM to the extent allowed by published data. We do not discuss results for all LHM combined because diseases in this group are clinically and pathologically heterogeneous, and thus probably etiologically distinctive.

We did not perform meta-analyses because our evaluation of the individual studies determined that the literature is too heterogeneous, that is, inconsistent, with respect to disease classification and exposure assessment, and therefore, quantitative risks are not appropriately combined. Moreover, the number of independent studies with comparable exposure circumstances (i.e., the same industry or occupation) and similar exposure assessments was too small to justify meta-analyses of these subsets of results. We were especially concerned about combining studies of different groups of workers with poorly characterized circumstances of exposure to formaldehyde. Several previous meta-analyses [35-38] have been performed, yielding variable conclusions, which may result from different methods and the underlying heterogeneity of exposure and health outcome data specificity and validity among published studies. In our opinion, the apparent gain in precision from a meta-analysis would be offset by problems in the interpretation of the summary results. We do, however, provide Forest plots of overall study findings as Figs. 1, 2, 3, 4, and 5.
Epidemiologic literature

Associations between formaldehyde exposure and the LHM have been investigated among anatomists, pathologists, embalmers, and industrial workers involved in the manufacture and use of formaldehyde and formaldehydecontaining products, such as resins, adhesives, wood products, fabrics, and garments. Formaldehyde has also been examined as a risk factor in numerous studies conducted in the general population, including populationbased case-control studies and analyses correlating occupations with LHM incidence and mortality. Accordingly, we present summaries of literature in tabular form separately for the following categories: cohort studies of industrial workers, cohort studies of professional workers, and population-based cohort and case-control studies.

Among all available literature, we regard two large occupational cohort studies as most informative because of the cohort design, greatest likelihood of exposure, quantification of exposure, and minimized bias and confounding. These are mortality studies of (1) a cohort of employees of ten US factories that produced or used formaldehyde, conducted by the US National Cancer Institute (henceforth termed the "NCI producers study") [39] ${ }^{1}$ and (2) a cohort of employees of six UK factories engaged in the production of resins, adhesives, and formalin (henceforth termed the "UK producers study") [48]. ${ }^{2}$

A second group of occupational studies that we regard as less informative includes a cohort of US garment workers [51-53] $]^{3}$ and a case-control analysis of deaths among US embalmers and funeral directors [54] that was based on a series of earlier proportionate mortality studies $[21,55,56]$. The study base in which the nested casecontrol study of LHM in the US embalmers and funeral directors study was conducted was poorly defined [54], and the formaldehyde exposure assessment in the garment workers study [53] was less specific and detailed than in the two "producers" cohort studies.

The remaining occupational studies reviewed were those conducted among cohorts of undertakers [57], pathologists [58], anatomists [59, 60], wood industry workers [61-63], and general chemical industry workers [20, 64-67]. In these studies, formaldehyde exposure was less certain than in aforementioned occupational cohort studies and, in many cases, was inferred from job title or work area.

The other major categories of epidemiologic studies reviewed were community-based cohort and case-control

\footnotetext{
${ }^{1}$ Previous publications of the NCI producers study include [40-47].

2 Previous publications of the UK producers study include [49, 50].

${ }^{3}$ Previous publications of the US garment workers include [51, 52].
} 


\section{STUDY}

Incuatry

Whong 1083 (formaldehyde-prod plant

Robinson $198 \pi$ (plywood prod)

Partanen 1093 (wood/plywood prod)

Adjekovio 1095 (nuto iron founcty)

Dell and Teta 1006 (plastics $\mathrm{m} / \mathrm{gr}$ )

Band 1997 fpulp \& paper work)

Rapiti 1997 (chemioal plent)

Coggon 2003 (proctuction)

Pinkerton 2004 (garment migr)

Ambroise 2005 (peet control work)

Beane Freoman 2009 (production)

Profecsional

Levine 1984 (undertakera)

Stroup 1986 (onatomiata)

Matanowaki 1909 (pathologista)

Hall 1991 (pathologista)

Hauptman 2009 (embalming)

Population -bresed

Linos 1980 (farm ocoupations) Linos 1980 (health occupationa)

Hansen 1095 ( $\infty 00 \mathrm{hx}$, penaion rec)*

Stellman 1998 (wood dusta)

*Formaldehyde exposure estimated

history reoorda.

Fig. 1 Forest plot of formaldehyde exposure and leukemias

1. $18[0.13,4.26]$

$0.59[0.02,14.67]$

$1.40[0.25,7.91]$

$0.43[0.05,1.57]$

$0.98[0.50,1.70]$

$0.85[0.63,1.13]$

$1.14[0.27,4.82]$

(1) [0.2

10070,1

$1.00[0 . \%, 1.6]$

$4.42[0.11,24.64]$

$1.0[0.85,1.22]$

$1.60[0.44,4.10]$

$1.50[0.70,2.70]$

$1.35[0.92,1.92]$

$1.25[0.26,3.65]$

$3.00[1.00,9.50]$

$0.70[0.30,1.20]$

$0.94[0.40,2.10]$

$1.00[0.80,1.40]$

0.96 [0.54, 1.71]

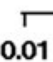

0.01

0.10
STUDY

Pinkerton 2004 (garment mfgr)

$1.44[0.80,2.37]$

Beane Freeman 2009 (production)

$0.90[0.67,1.21]$

Hauptmann 2000 (embalming)

$11.20[1.30,9560]$
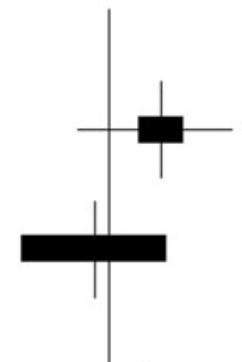

$\begin{array}{cccc}0.01 & 1.00 & 10.00 & 100.00\end{array}$

Fig. 2 Forest plot of formaldehyde exposure and myeloid leukemia

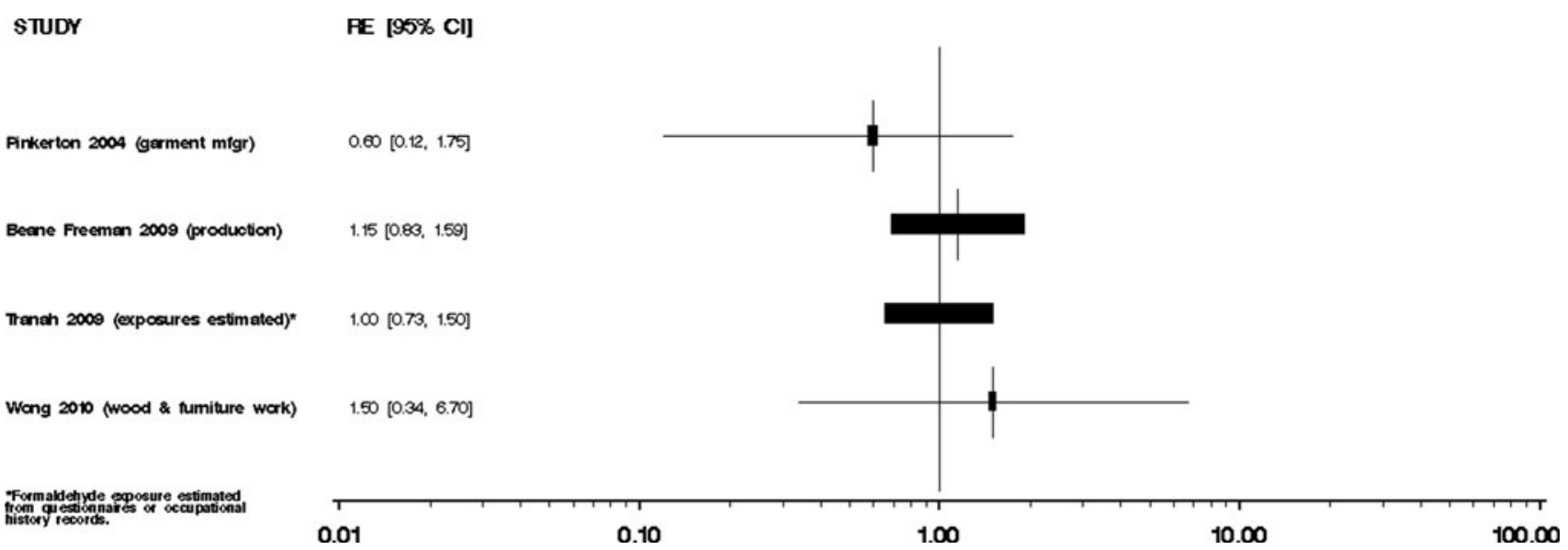

Fig. 3 Forest plot of formaldehyde exposure and chronic lymphocytic leukemia 
STUDY

Partanen 1993 (wood/plywood prod)

Hauptmann 2000 (embalming)
PE $[95 \% \mathrm{Cl}]$

$4 . œ[0.87,18.60]$

$1.10[0.50,2.10]$

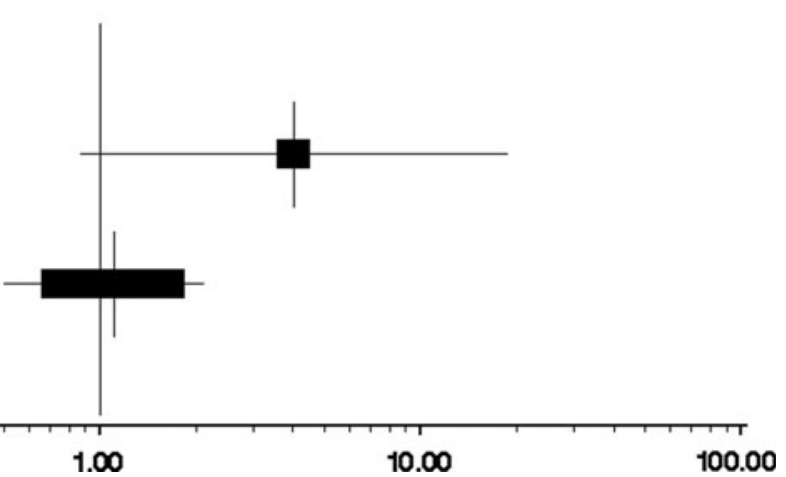

Fig. 4 Forest plot of formaldehyde exposure and lymphomas
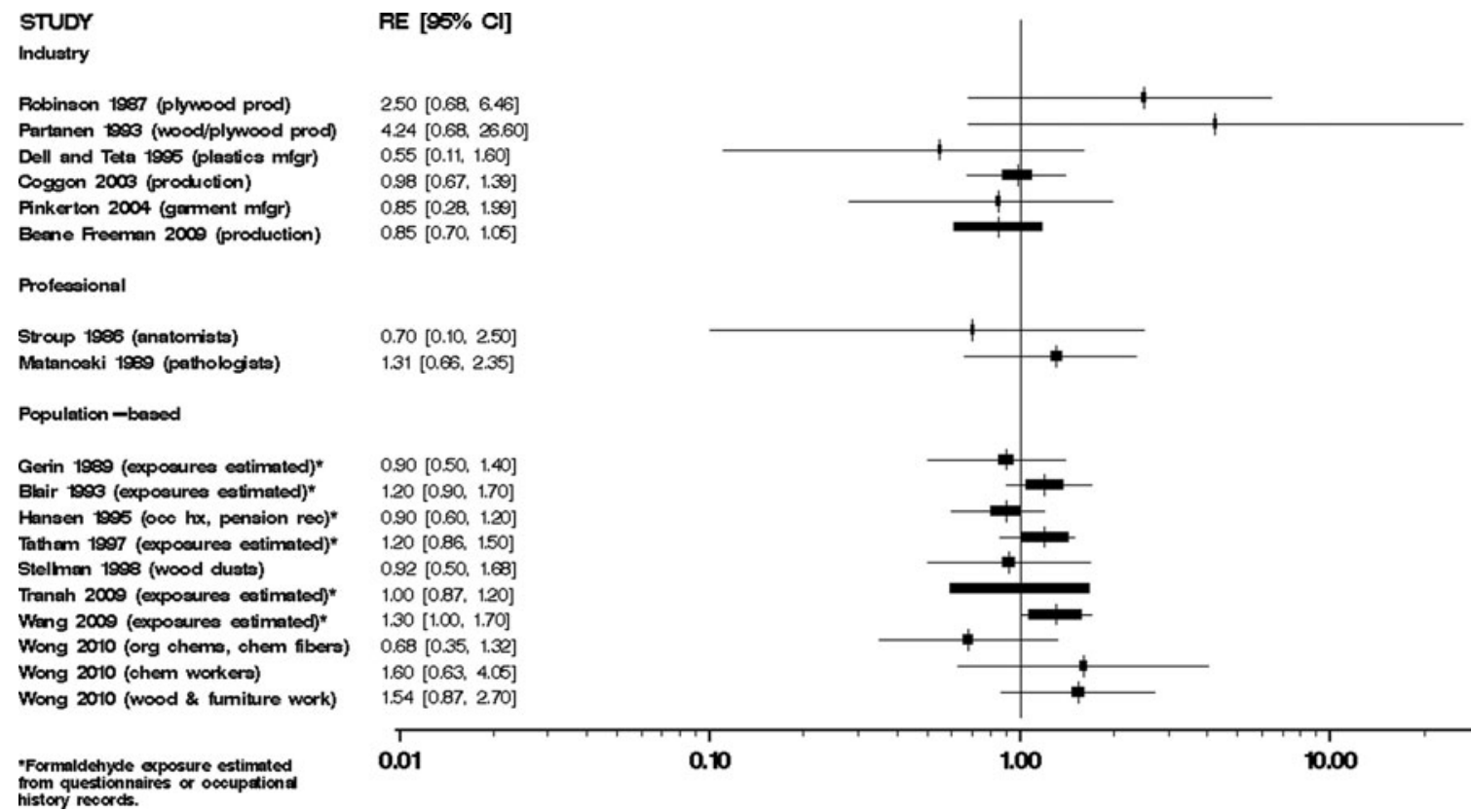

$0.70[0.10,2.50]$ $1.31[0.66,2.35]$

$0.90[0.50,1.40]$ $1.20[0.90,1.70]$ $0.90[0.60,1.20]$ $1.20[0.86,1.50]$ $0.92[0.50,1.6]$ $1.00[0.87,1.20]$ $1.30[1.00,1.70]$ $0.68[0.35,1.32]$ $1.60[0.63,4.05]$ $1.54[0.87,2.70]$

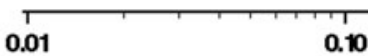

0.10

Fig. 5 Forest plot of formaldehyde exposure and non-Hodgkin lymphoma

studies and general population surveys, which also provide limited information on formaldehyde exposure and LHM risks. Exposure assessment in these studies was generally based on crude exposure metrics, such as "low" versus "high" exposure probability combinations of heterogeneous job titles. Details of study design and exposure assessment for the studies reviewed are summarized in Table 1.

\section{Results}

Summary of leukemia findings

The findings for the occupational cohort studies with leukemia outcomes are summarized in Table 2. The two most influential studies are considered first. Based on comparisons with national rates, no excesses for all leukemia (standardized mortality ratio (SMR) 1.02, $95 \%$ confidence interval (CI) $0.85-1.22$ ) or myeloid leukemia (SMR 0.90, $95 \%$ CI 0.67-1.21) were found in the most recent followup of the NCI producers' study. Among the formaldehydeexposed portion of the cohort, there was a weak trend of relative risk (RR) with peak exposure, for both all leukemias and myeloid leukemia, largely influenced by elevated RRs of 1.78 (95\% CI 0.87-3.64) for myeloid leukemias and 1.42 (0.92-2.18) for "other" (non-myeloid) leukemias in the highest peak exposure category. However, most of the trends and individual RR estimates were not remarkable or precise. The association for peak exposure and myeloid leukemia was considerably attenuated from the previous follow-up of the cohort, RR 2.79 (95\% CI 1.08-7.21, 14 cases, p-trend 0.02) at the highest peak category. Beane Freeman [39] corrected the results published in Hauptmann [47] that inadvertently omitted 1,006 deaths, 


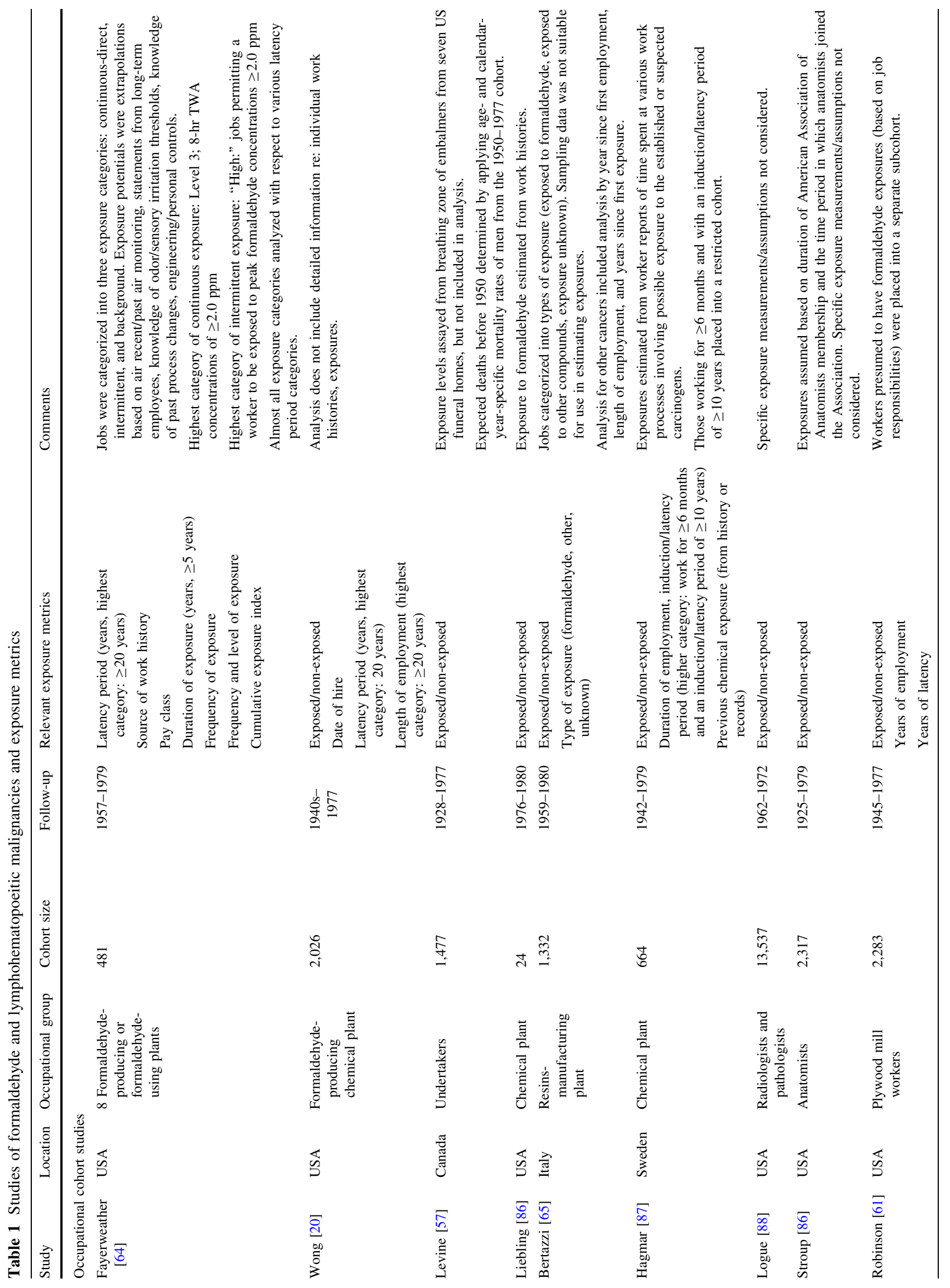









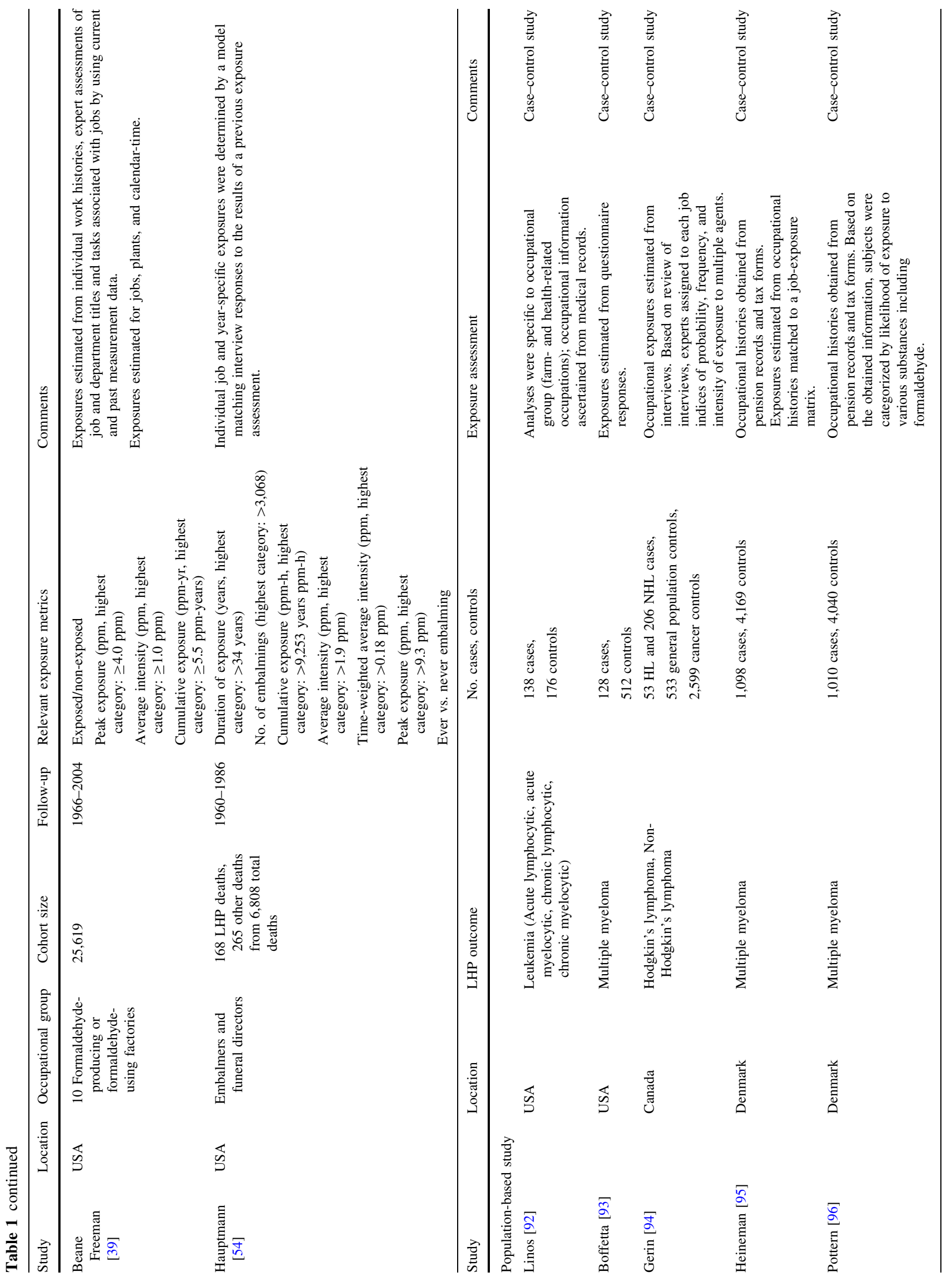




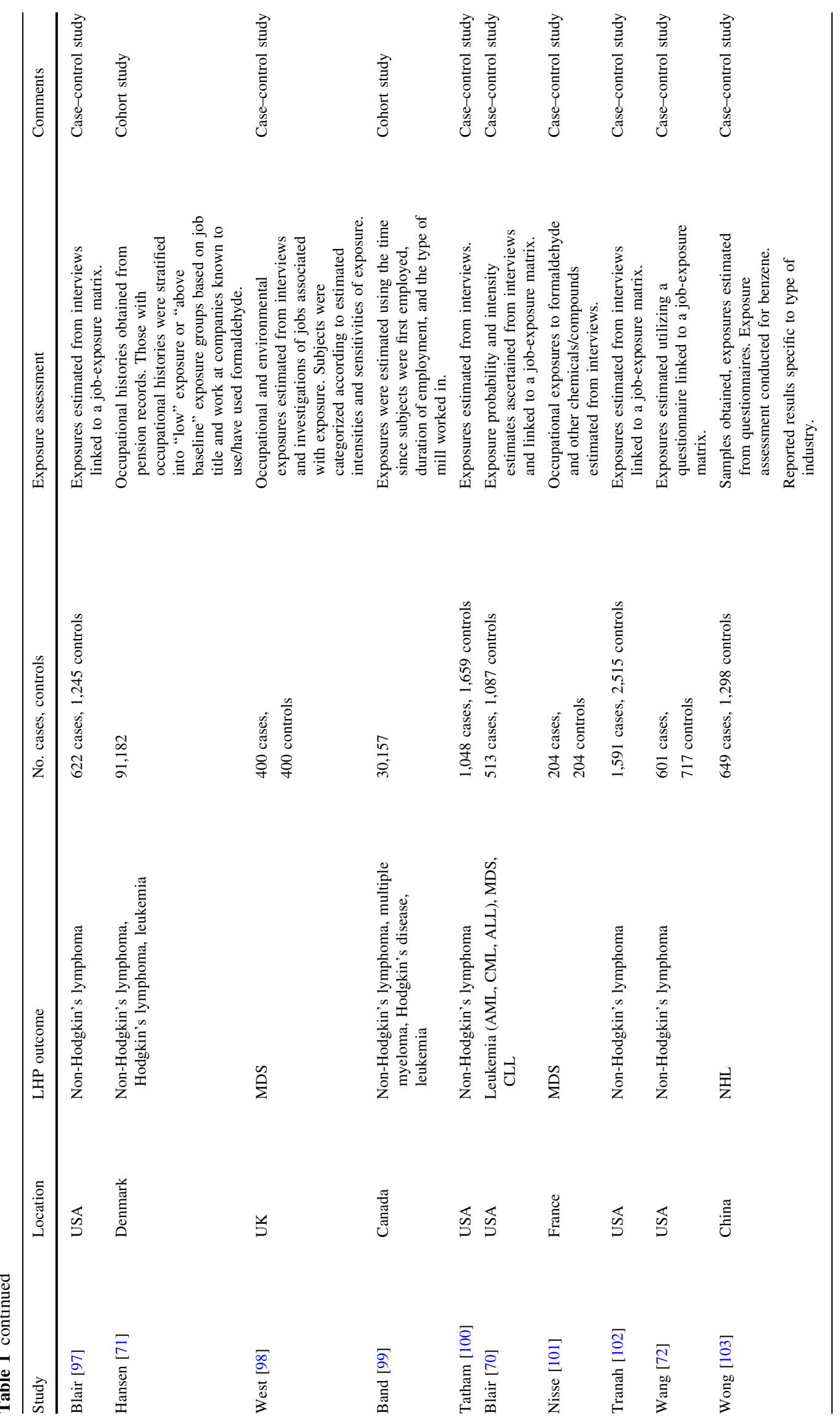


including 22 LHM deaths. No clear associations with average or cumulative exposure were found in the corrected data for any of the leukemias. Null findings were reported for lymphatic leukemia and "other and unspecified leukemia" [39].

Leukemia mortality was not elevated overall (SMR $0.91,95 \%$ CI $0.62-1.29$ ) or in the most highly exposed (i.e., jobs with $>2 \mathrm{ppm}$ formaldehyde) segment (SMR $0.71,95 \%$ CI $0.31-1.39$ ) of the UK formaldehyde producers study [48]. No separate results for myeloid leukemias were presented.

Among other occupational studies, the nested casecontrol analysis of US embalmers reported odds ratios for myeloid leukemias and for acute myeloid leukemias in the range of 2.0-3.2 for number of embalmings, and for cumulative and peak formaldehyde exposure categories, relative to the referent group that performed $<500$ career embalmings. However, the underlying sample of death certificates evaluated in this analysis demonstrated no excess of myeloid leukemias: the 29 myeloid leukemias reported in this study generated a proportionate mortality ratio (PMR) of 1.08 (95\% CI 0.70-1.56), and the subset of 20 acute myeloid leukemias generated a PMR of 1.16 (0.71-1.79) [68]. Moreover, there was little evidence of increasing exposure-response trends in the non-reference exposure categories [54]. In the study of US garment workers, the SMR for leukemia deaths was 1.09 (95\% CI 0.7-1.62), based on 24 total leukemia deaths. For the 15 observed myeloid leukemias, the SMR was 1.44 (95 \% CI 0.8-2.37), and for the nine acute myeloid leukemias, the SMR was 1.34 (95\% CI 0.66-2.54). In the US garment workers study, SMRs were increased among workers with $\geq 10$ years exposure (SMR for myeloid leukemia $2.19,95 \%$ CI $0.95,4.32)[69]^{4}$ and $\geq 20$ years since first exposure (SMR 1.91, $95 \%$ CI 1.02, 3.27) ${ }^{5}$ [53].

No excesses were observed for all leukemia or for leukemia subtypes among persons classified as exposed to formaldehyde in the population-based case-control studies [70, 71]. In the remaining occupational studies, risk estimates for leukemia compared with the national or regional populations were consistently close to the null value and unstable due to small numbers.

The RR estimate was 5.79 (95\% CI 1.44, 23.25) for leukemia among the combined exposure group of "formaldehyde-exposed and wood-related occupations" in the American Cancer Society Cancer Prevention Study II; however, this result was based on only two deaths. The RR

\footnotetext{
$495 \%$ CI calculated from data presented in manuscript based on method described by Rothman and Boice [69].

$595 \%$ CI calculated from data presented in manuscript based on method described by Rothman and Boice [69].
}

for those with formaldehyde exposure only was 0.96 (95\% CI 0.54-1.71), based on 12 leukemia deaths [63].

\section{Summary of lymphoma findings}

The lymphoma results, including those for chronic lymphocytic leukemia (CLL) when reported separately, are summarized in Table 3. With the exception of Hodgkin lymphoma (HL), there were no overall excesses of the lymphomas among exposed workers in the NCI producers cohort; HL risk was associated with peak exposure, with relative risk reaching 3.96 (95\% CI 1.31-12.02) only at the highest exposure category $(\geq 4.0 \mathrm{ppm})$, based on 11 deaths. A similar, but weaker, trend was observed for HL and average exposure (RR 2.48, $95 \%$ CI 0.84-2.32) at the highest category [39]. The only overall excess for any of the lymphomas reported in the UK producers study was a weak association for multiple myeloma (MM) in the subgroup classified as mostly highly exposed workers (SMR 1.18 , $95 \%$ CI 0.48-2.44) [48]. Quantitative exposureresponse findings were not presented.

Results of the nested case-control study of embalmers presented for all neoplasms of lymphoid origin, rather than for non-Hodgkin lymphoma (NHL) or MM specifically, did not suggest an association with any indices of formaldehyde exposure [54]. SMRs for lymphoma were less than 1.0 in the US garment workers study [53]. None of the other occupational cohort studies reported a significantly increased risk of NHL, HL, or MM (Table 3). Risk estimates for NHL, HL, and MM in community-based studies also suggested no association, with RR estimates ranging between 0.5 and 1.3, although positive results were reported in one NHL study from Connecticut [72]. Several community-based studies provided results for NHL subtypes, but there were no consistent associations [59-62].

\section{Discussion}

The main considerations pertinent to assessing epidemiological evidence for a causal relation between formaldehyde exposure and the leukemias or other specific LHM are consistency of findings across studies, evidence for exposure-response associations, accuracy of exposure and health outcome assessment, and minimal confounding and bias. The extent to which exposure assessment in a given study is valid, accurate, and, ideally, permits quantitative dose-response estimation is a critical aspect of research quality. Secondarily, epidemiologic findings suggestive of an association should be interpreted in relation to available evidence of mechanisms of pathogenesis.

The epidemiologic literature provides little or no evidence indicating excess risks overall or exposure-response 


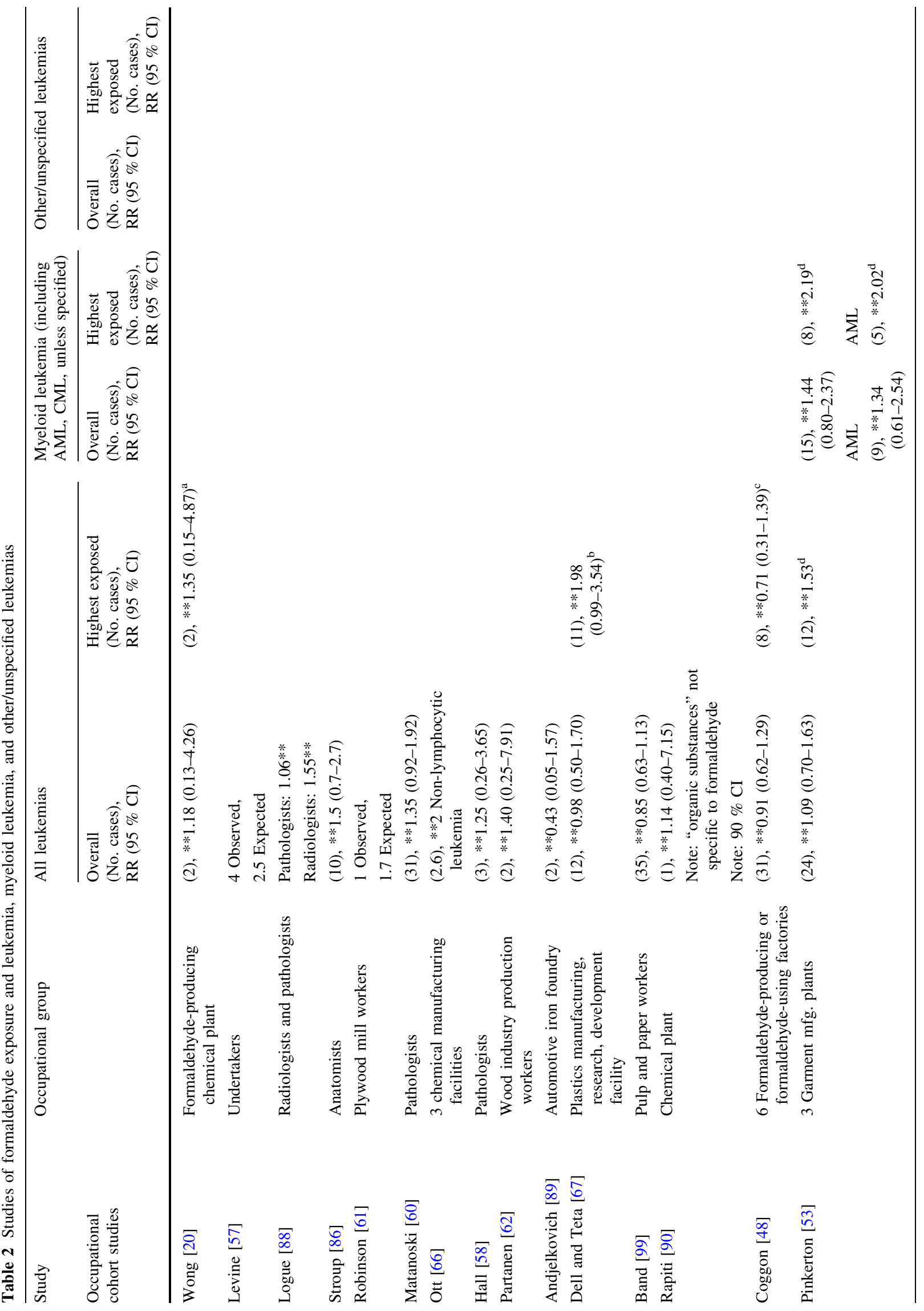




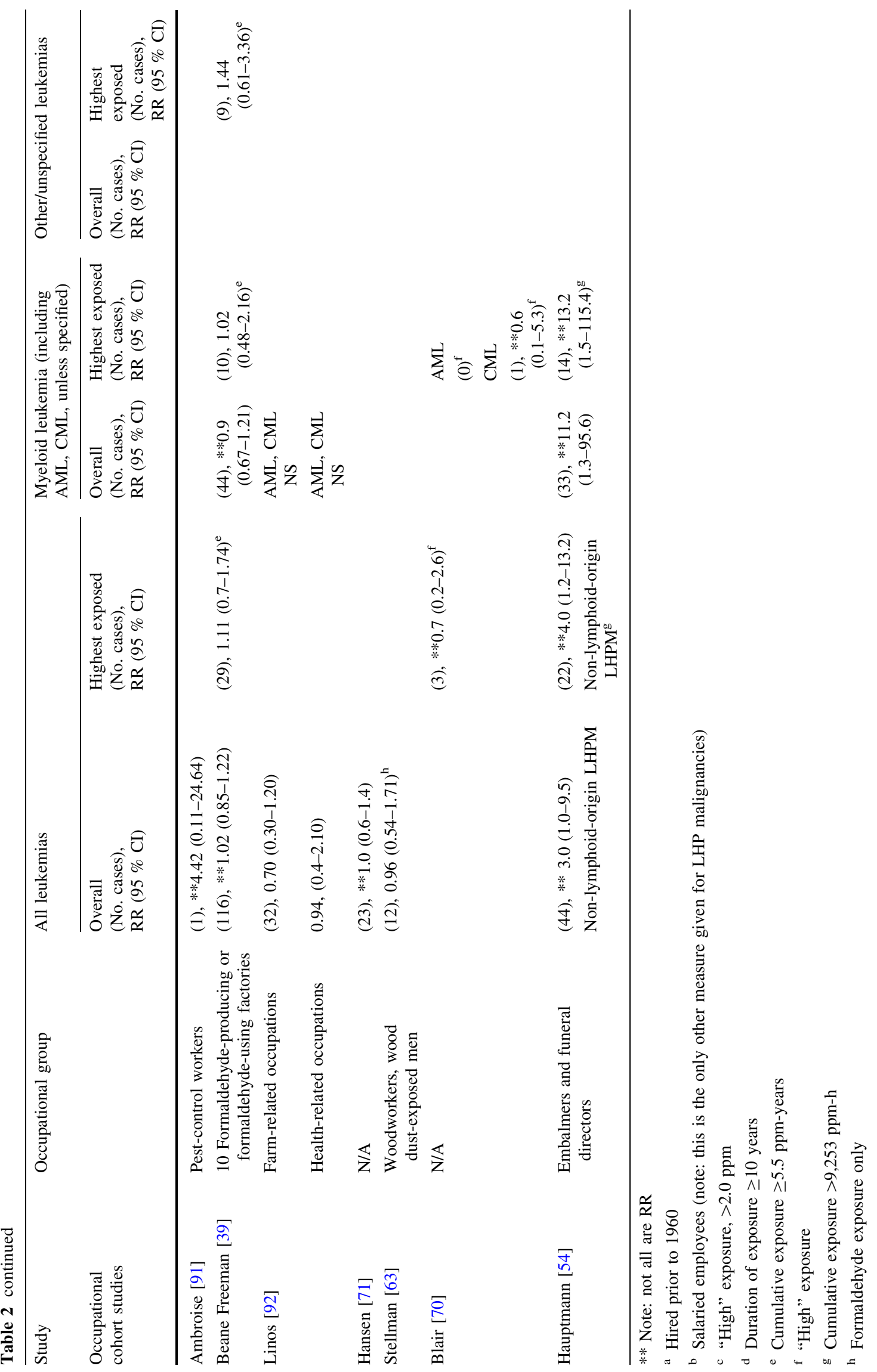




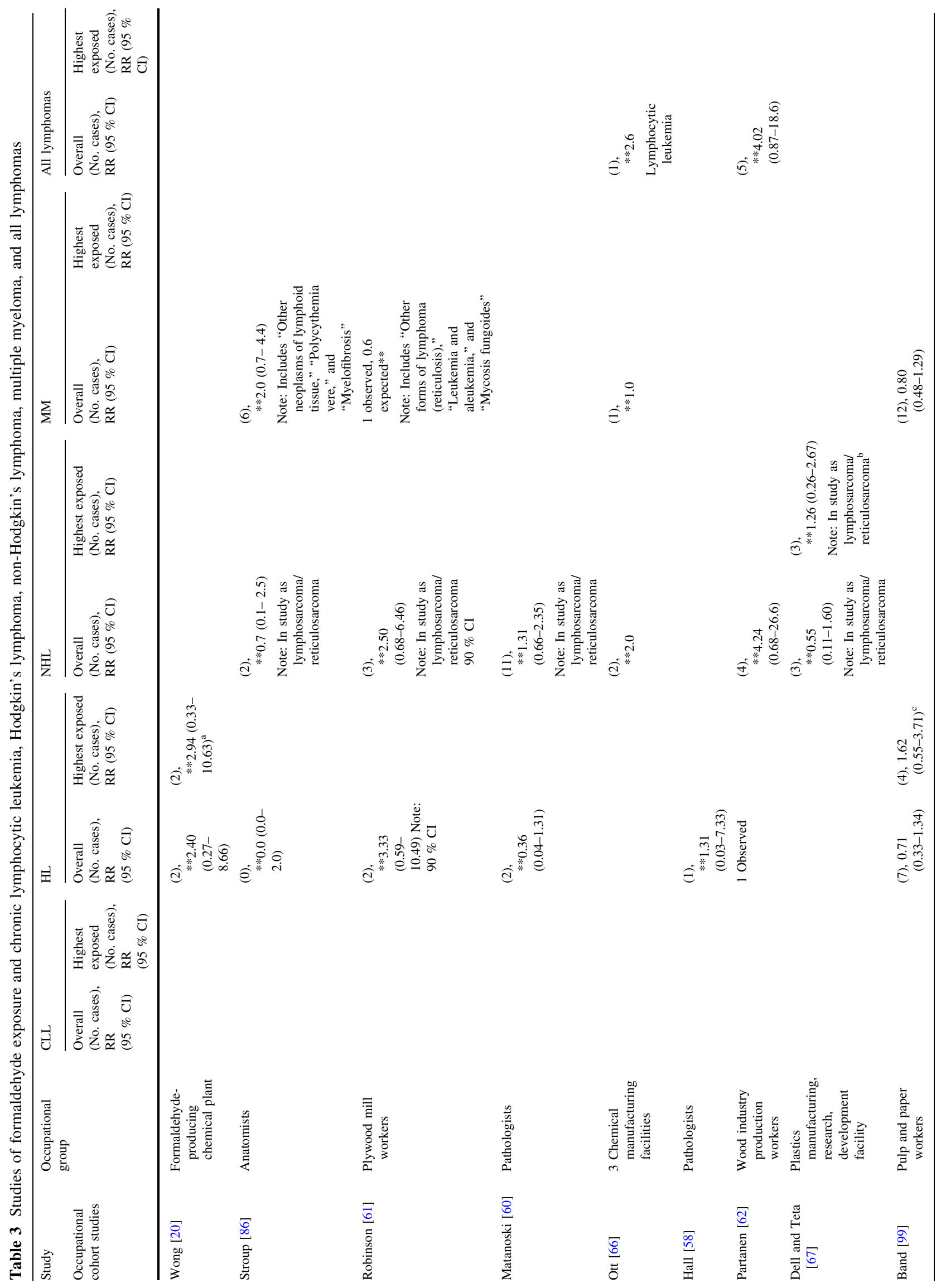




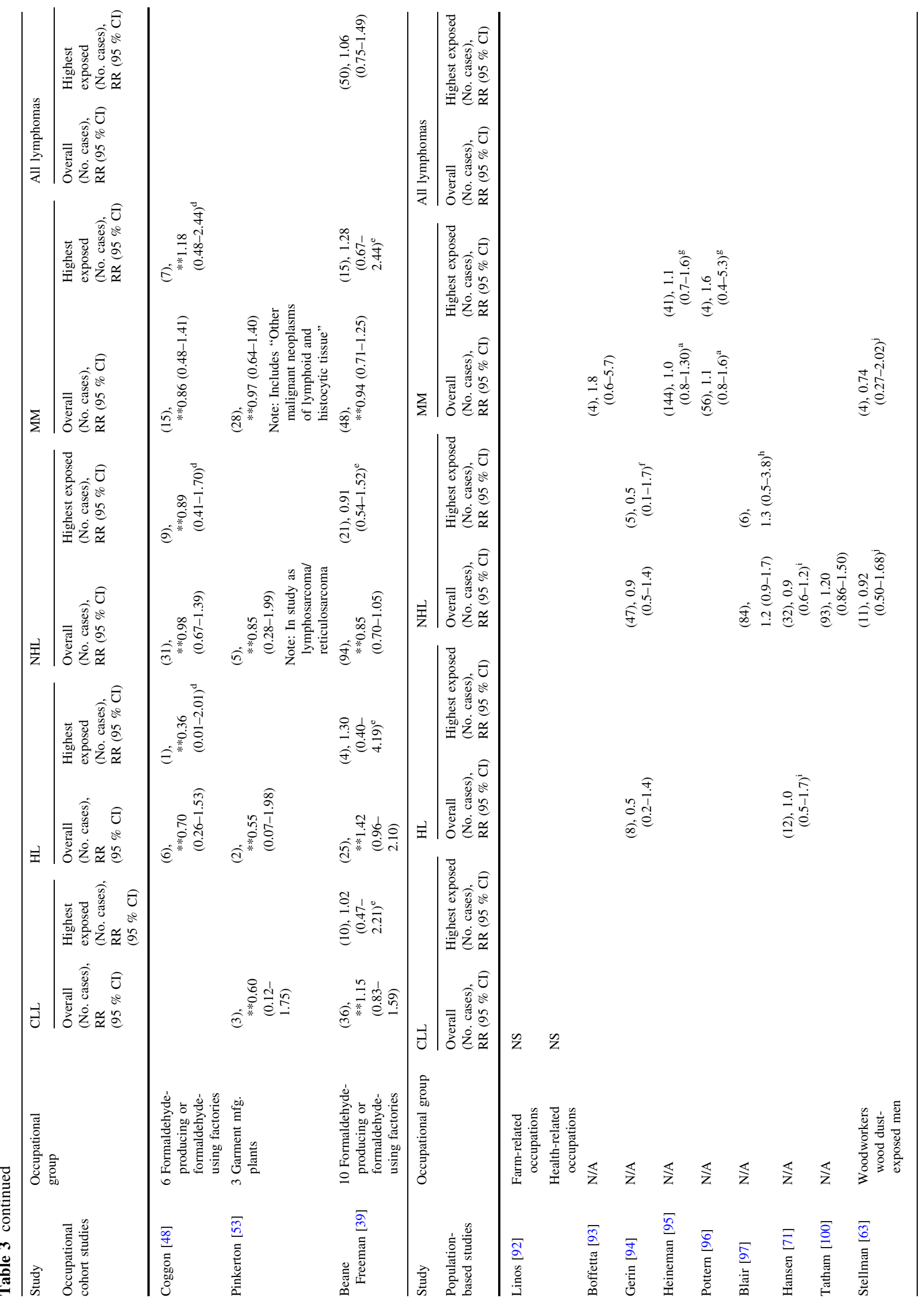




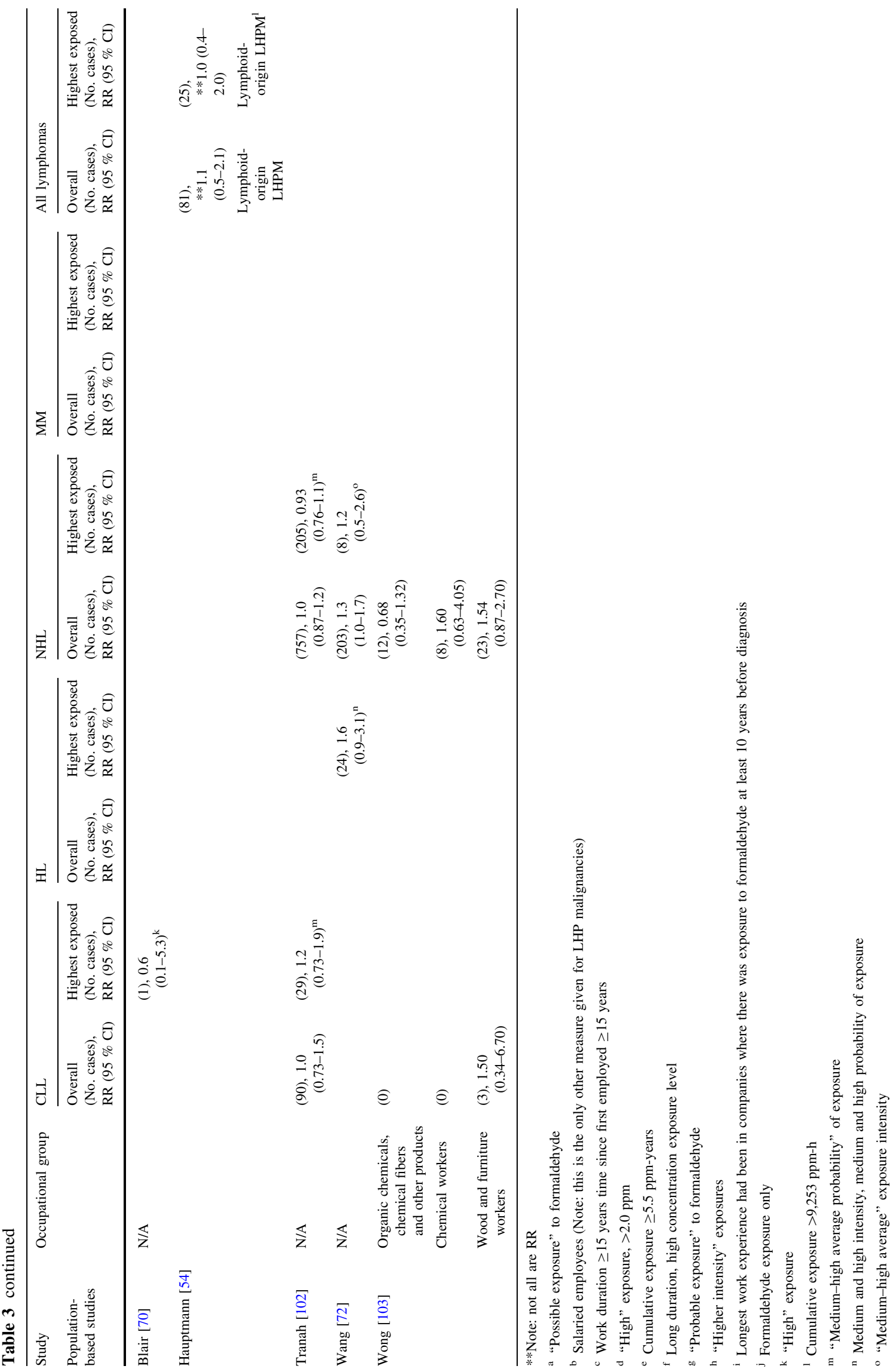


associations between formaldehyde and any of the LHM, including leukemias, myeloid leukemias, and acute myeloid leukemias. In the majority of occupational cohort studies, which we regard as most informative, specific LHM risk estimates were consistent with the null value, with few exceptions, where the excesses were generally small (i.e., RR $<1.5$ ) and statistically imprecise.

The NCI producers cohort [39] and the nested casecontrol analysis of the embalmers and funeral directors group [54] found elevated risk estimates based on some exposure metrics compared with an internal reference group. However, the increased relative risk for myeloid leukemia noted in an earlier follow-up of the NCI producers cohort [47] had diminished in the most recent update [39].

The strongest associations for myeloid leukemia observed in this cohort were with peak exposures; whereas cumulative exposure and average exposure intensity were unrelated to risk. As described in the original publication on the exposure assessment of the NCI producers study [73], there was no uniform definition of peak exposure. Instead, peak was defined on a job-specific basis as an excursion (usually of short duration, e.g., $<15 \mathrm{~min}$ ) relative to the estimated average exposure for the job. Moreover, epidemiologic associations of a specific disease with peak exposure can be difficult to interpret in the absence of prior mechanistic support, such as the requirement for acute above-threshold exposures. In general, established human carcinogens show strong and consistent associations between unbiased measures of cumulative exposure and cancer risk, and cumulative exposure is the default dose metric that is mostly used to assess cancer risk for etiologic exposures. A re-analysis of the data from the previous follow-up [47] corroborated the absence of associations with cumulative exposure but also indicated no consistent associations between myeloid leukemia and either duration of time worked at the highest peak or time since highest peak exposure [45]. Findings from similar re-analyses have not been reported for the most recent follow-up. In the other relatively strong occupational cohort study [48], there was no association between formaldehyde exposure and leukemia.

Among the other occupational studies, the US embalmers study generated elevated odds ratios for some formaldehyde exposure metrics [54]. However, as noted by Cole et al. [68], this study has notable limitations-including a lack of overall excess leukemia risks (based on PMR analysis), exposure assessment uncertainties, and a poorly defined study base originating from a convenience sample of death certificates obtained from previous proportionate mortality studies. In the study of US garment workers [53], the only support for an association with formaldehyde was the observation of moderately elevated relative risks for myeloid leukemia associated with long-term exposures and longest follow-up that are very crude exposure metrics correlated with older age. The results of the remaining lower-quality studies are not supportive of an association between formaldehyde exposure and leukemia risk. Another recent review of the literature reached similar conclusions for associations with the leukemias [74].

The pattern of epidemiological results for the lymphomas is inconsistent. In the NCI producers cohort, there were some notably elevated relative risks (in the range of 2.5-4.0) observed for exposure categories of highest peak for HL and MM [39, 47], yet null or at most very small excesses for these diseases were reported in the other studies of occupational formaldehyde exposure.

Consistency with toxicological and mechanistic evidence

Studies of workers in China have evaluated a potential association between exposure to formaldehyde and a change in one or more blood parameters indicative of hematotoxicity [75-77]. Evidence suggestive of pancytopenia and leukemia-specific chromosome changes was reported from a study of Chinese formaldehyde melamine resinexposed workers [78]. However, the blood cell parameters among exposed workers were largely within the normal range for Chinese populations [79-82], and the chromosome findings were based on the progeny of circulating stem cells from a small numbers of workers $(n=10-12)$ after 14 days of culture. Overall, the available data do not provide evidence of a clinically or biologically relevant impact on blood cell parameters in humans following exposure to formaldehyde.

Although mechanisms for the development of leukemia or lymphoma following exposure to formaldehyde have been hypothesized [75], they remain speculative. Notably, proposed mechanisms rely heavily on the assumption that formaldehyde can have direct effects on cells or tissues beyond the portal of entry. One fundamental mechanistic question critical to these hypotheses is whether exogenously derived formaldehyde can enter the circulating bloodstream and subsequently damage circulating precursor cells or the bone marrow. Recent experimental research, using extremely sensitive assays with the power to detect as little as one exogenous DNA adduct in 10 billion deoxyguanosines, demonstrated identical endogenously formed DNA formaldehyde adducts in all rat and nonhuman primate non-portal-of-entry tissues, including bone marrow. No exogenous adducts were detected in any distant tissue [83-85]. These considerations call into question the plausibility of causal links between formaldehyde and the LHM. 


\section{Conclusions and recommendations}

Existing epidemiologic evidence does not provide convincing support that formaldehyde causes any of the LHMs, including myeloid leukemia. Findings among the highest quality occupational cohort studies are largely null, the positive findings are inconsistent in terms of strength and specificity of association, and there are only isolated instances of exposure-response relations. Epidemiologic evidence from other formaldehyde-exposed occupational cohorts is similarly inconsistent, is often based on small numbers of events, and suffers from a greater likelihood of exposure misclassification and other potential limitations than the two large industrial cohort studies that we regard as highest quality. Available community-based studies, which generally have superior diagnostic classification but poorer quality exposure assessment than in the occupational cohort mortality studies, provide no support for etiologic associations of formaldehyde with any of the LHM.

Although we conclude that a causal connection between formaldehyde exposure and LHM is not supported by existing epidemiologic findings and that the evidence is further weakened by the absence of established carcinogenic mechanisms for the LHM, we nevertheless encourage further epidemiologic research on this topic. We make this recommendation with the caveat that, in order to be informative, further research should offer substantive improvements over the existing body of studies, especially in terms of application of modern diagnostic criteria for specific LHM and individual level quantitative exposure assessment. Well-defined occupational cohort studies should offer the best opportunities to evaluate associations between formaldehyde exposure and LHM risks. Because formaldehyde exposure is ubiquitous, accurately characterizing exposures from the many possible sources, including combustion, household furnishings, automobiles, and consumer products, is essentially impossible. Workplace exposures, on the other hand, are typically substantially higher than exposures from other environmental sources. Continued follow-up of the established high-quality occupational cohorts would be worthwhile, although the scientific yield may be limited because exposure and health outcome misclassification limitations can probably not be remedied. Re-analyses, including sensitivity analysis, of existing datasets may add insight into reported findings, as evidenced by previous reanalyses of the NCI producers cohort data [45]. Specifically, additional statistical analyses of risks of specific LHM in relation to the various exposure metrics in the original NCI producers study [73] are warranted.

A more attractive-but also more complicated and expensive-option would be to enumerate and follow new occupational cohorts exposed to formaldehyde. Professional groups, such as anatomists, pathologists, funeral directors, and embalmers, may be the most appropriate study populations because their exposures are frequent, generally remain at relatively high intensity, and may not be confounded by other potential exposures to leukemogens, such as benzene. Another advantage to studying such professions is that they are comprised of persons with comparable socioeconomic status, a characteristic often associated with baseline rates of LHM in the population.

In contrast, new cohort studies of industrial workers would likely encounter problems related to vastly reduced exposures in large workplaces during the past several decades in many high-income countries, and the resulting reduced capacity to test exposure-related associations rigorously. New occupational cohort studies in developing economies may offer opportunities for further research. Any new occupationally based studies should strive to obtain incidence data with modern LHM classification, and to incorporate valid, thorough exposure assessments for formaldehyde and potential confounders. Cross-sectional and, preferably, prospective investigations of biomarkers of bone marrow toxicity relevant to carcinogenesis that have adequate statistical power would also be worthwhile and might be incorporated into cohort studies where feasible (e.g., on subsets of workers).

In summary, we find insufficient epidemiologic evidence to support a causal relation between formaldehyde exposure and leukemia, including myeloid leukemia. We find no clear evidence of an excess risk of leukemia or myeloid leukemia in any large, well-conducted study. Furthermore, we find the occasional positive associations between various exposure metrics and leukemia or myeloid leukemia risk to be inconsistent, and in some instances, contradictory to results based on more conventional exposure characterization approaches. We also find no epidemiologic basis on which to conclude that formaldehyde causes any of the lymphomas. Further weakening arguments for causal associations is the absence of well-defined plausible models of pathogenesis. Nevertheless, in view of the ubiquitous presence of formaldehyde in the population and experimental evidence indicating high-dose carcinogenic potential, at least for portalof-entry sites, we recommend improved epidemiologic research on potential risks for the LHM.

Acknowledgments ENVIRON acknowledges receipt of a grant from the Research Foundation for Health and Environmental Effects ${ }^{\circledR}$ (RFHEE), a 501(c)(3) tax-exempt organization established by the American Chemistry Council (ACC) to conduct this review. RFHEE had no role in reviewing or interpreting the epidemiologic literature or in preparing or revising the manuscript. Drs. Checkoway and Boffetta received financial support from ENVIRON for their time in reviewing the literature and drafting and revising the manuscript. The authors are grateful for the contributions of the following colleagues who provided helpful comments on the draft manuscript: Dr. Philip Cole, University of Alabama, Dr. Jack Mandel, Exponent, Dr. Gary Marsh, University of Pittsburgh, Dr. Morel Symons, 
du Pont, Dr. Patricia Buffler, U California, Berkeley, Dr. David Coggon, University of Southampton, UK, Dr. David Savitz, Brown University. We especially appreciate the contributions of Dr. Robinan Gentry and Dr. James Swenberg to the section summarizing the mechanistic evidence and of Ms. Farah Chowdhury for creating summary tables.

Open Access This article is distributed under the terms of the Creative Commons Attribution License which permits any use, distribution, and reproduction in any medium, provided the original author(s) and the source are credited.

\section{References}

1. Neuberger A (1981) The metabolism of glycine and serine. In: Neuberger A, van Deenen LLM (eds) Comprehensive biochemistry, vol 19A. Elsevier, Amsterdam, pp 257-303

2. Kim KH, Jahan SA, Lee JT (2011) Exposure to formaldehyde and its potential human health hazards. J Environ Sci Health C Environ Carcinog Ecotoxicol Rev 29(4):277-299

3. Madrid PA, Sinclair H, Bankston AQ et al (2008) Building integrated mental health and medical programs for vulnerable populations post-disaster: connecting children and families to a medical home. Prehosp Disaster Med 23(4):314-321

4. Parthasarathy S, Maddalena RL, Russell ML, Apte MG (2011) Effect of temperature and humidity on formaldehyde emissions in temporary housing units. J Air Waste Manag Assoc 61(6):689-695

5. Bolt HM (1987) Experimental toxicology of formaldehyde. J Cancer Res Clin Oncol 113(4):305-309

6. Malorny G, Rietbrock N, Schneider M (1965) The oxidation of formaldehyde to formic acid in the blood, a contribution to the metabolism of formaldehyde. Naunyn Schmiedebergs Arch Exp Pathol Pharmakol 250:419-436

7. Uotila L, Koivusalo M (1987) Formaldehyde dehydrogenase from human erythrocytes: purification, some properties and evidence for multiple forms. Prog Clin Biol Res 232:165-177

8. Heck H, Casanova M (2004) The implausibility of leukemia induction by formaldehyde: a critical review of the biological evidence on distant-site toxicity. Regul Toxicol Pharmacol 40(2): 92-106

9. Smith DL, Bolyard M, Kennedy ER (1983) Instability of formaldehyde air samples collected on a solid sorbent. Am Ind Hyg Assoc J 44(2):97-99

10. Szende B, Tyihak E (2010) Effect of formaldehyde on cell proliferation and death. Cell Biol Int 34(12):1273-1282

11. McGwin G Jr, Lienert J, Kennedy JI Jr (2011) Formaldehyde exposure and asthma in children: a systematic review. Cien Saude Colet 16(9):3845-3852

12. Songur A, Ozen OA, Sarsilmaz M (2010) The toxic effects of formaldehyde on the nervous system. Rev Environ Contam Toxicol 203:105-118

13. Duong A, Steinmaus C, McHale CM, Vaughan CP, Zhang L (2011) Reproductive and developmental toxicity of formaldehyde: a systematic review. Mutat Res 728(3):118-138

14. Swenberg J, Kerns W, Pavkov K, Mitchell R, Gralla EJ (1980) Carcinogenicity of formaldehyde vapor: interim findings in a long-term bioassay of rats and mice. Dev Toxicol Environ Sci 8:283-286

15. Swenberg JA, Kerns WD, Mitchell RI, Gralla EJ, Pavkov KL (1980) Induction of squamous cell carcinomas of the rat nasal cavity by inhalation exposure to formaldehyde vapor. Cancer Res 40(9):3398-3402

16. Jensen OM (1980) Cancer risk from formaldehyde. Lancet 2(8192):481-482
17. Griesemer RA, Ulsamer AG, Arcos JC, Beall JR (1982) Report of the federal panel on formaldehyde. Environ Health Perspect 43: 139-168

18. Marsh GM (1982) Proportional mortality patterns among chemical plant workers exposed to formaldehyde. Br J Ind Med 39(4):313-322

19. Walrath JFJ (1982) Proportionate mortality among New York elbalmers. In: Proceedings of the third annual CIIT conference: formaldehyde toxicity. Hemisphere Publishing Corporation, New York

20. Wong O (1983) An epidemiologic mortality study of a cohort of chemical workers potentially exposed to formaldehyde with a discussion on SMR and PMR. In: Gibson JE (ed) Formaldehyde toxicity. Hemisphere Publishing Corp, New York, pp 256-272

21. Walrath J, Fraumeni JF Jr (1984) Cancer and other causes of death among embalmers. Cancer Res 44(10):4638-4641

22. Harrington JM, Shannon HS (1975) Mortality study of pathologists and medical laboratory technicians. Br Med J 4(5992): 329-332

23. IARC (2006) Formaldehyde, 2-Butoxyethanol and 1-tert-Butoxypropan-2-ol. Monograph, 88th edn. International Agency for Research on Cancer, Lyons

24. Baan R, Grosse Y, Straif K et al (2009) A review of human carcinogens-part F: chemical agents and related occupations. Lancet Oncol 10(12):1143-1144

25. National Toxicology Program (2011) Report on Carcinogens, Twelfth Edition. US Department of Health and Human Services, Public Health Service, National Toxicology Program, pp iii-499

26. EPA (2010) IRIS toxicological review of formaldehyde-inhalation assessment (External Review of Draft). U.S. Environmental Protection Agency, Washington, DC

27. National Research Council (2011) Review of the environmental protection agency's draft IRIS assessment of formaldehyde. The National Academies Press, Washington, DC

28. IARC (2006) Preamble. IARC Monographs on the Evaluation of Carcinogenic Risks to Humans, Lyon

29. IOM (2003) Identifying and evaluating the literature. In: Grossblatt N, Kelly K (eds) Gulf war and health. Volume 2 insecticides and solvents. National Academies Press, Washington, DC

30. Moher D, Liberati A, Tetzlaff J, Altman DG (2009) Preferred reporting items for systematic reviews and meta-analyses: the PRISMA statement. Ann Int Med 151(4):264-269 (W64)

31. West S, King V, Carey TS et al. (2002) Systems to rate the strength of scientific evidence. AHRQ Publication No. 02-E016 ed. Agency for Healthcare Research and Quality, Rockville, MD

32. WHO (1977) International statistical classification of diseases, injuries, and causes of death, 9th revision edn. World Health Organization, Geneva

33. Morton LM, Turner JJ, Cerhan JR et al (2007) Proposed classification of lymphoid neoplasms for epidemiologic research from the pathology working group of the international lymphoma epidemiology consortium (InterLymph). Blood 110(2): 695-708

34. Turner JJ, Morton LM, Linet MS et al (2010) InterLymph hierarchical classification of lymphoid neoplasms for epidemiologic research based on the WHO classification (2008): update and future directions. Blood 116(20):e90-e98

35. Bachand AM, Mundt KA, Mundt DJ, Montgomery RR (2010) Epidemiological studies of formaldehyde exposure and risk of leukemia and nasopharyngeal cancer: a meta-analysis. Crit Rev Toxicol 40(2):85-100

36. Collins JJ (2004) Formaldehyde exposure and leukaemia. Occup Environ Med 61(11):875-876

37. Zhang L, Steinmaus C, Eastmond DA, Xin XK, Smith MT (2009) Formaldehyde exposure and leukemia: a new meta-analysis and potential mechanisms. Mutat Res 681(2-3):150-168 
38. Bosetti C, McLaughlin JK, Tarone RE, Pira E, La VC (2008) Formaldehyde and cancer risk: a quantitative review of cohort studies through 2006. Ann Oncol 19(1):29-43

39. Beane Freeman LE, Blair A, Lubin JH et al (2009) Mortality from lymphohematopoietic malignancies among workers in formaldehyde industries: The National Cancer Institute Cohort. JNCI J Natl Cancer Inst 101(10):751-761

40. Blair A, Stewart P, O’Berg M et al (1986) Mortality among industrial workers exposed to formaldehyde [see comments]. J Natl Cancer Inst 76(6):1071-1084

41. Blair A, Stewart PA (1989) Comments on the reanalysis of the National Cancer Institute study of workers exposed to formaldehyde. J Occup Med 31(11):881-884

42. Stewart PA, Rice C (1990) A source of exposure data for occupational epidemiology studies. Appl Occup Environ Hyg 5(6):359-363

43. Marsh GM, Stone RA, Esmen NA, Henderson VL (1994) Mortality patterns among chemical plant workers exposed to formaldehyde and other substances. $\mathrm{J}$ Natl Cancer Inst 86(5):384-386

44. Marsh GM, Stone RA, Esmen NA, Henderson VL, Lee KY (1996) Mortality among chemical workers in a factory where formaldehyde was used. Occup Environ Med 53(9):613-627

45. Marsh GM, Youk AO (2004) Reevaluation of mortality risks from leukemia in the formaldehyde cohort study of the National Cancer Institute. Regul Toxicol Pharmacol 40(2):113-124

46. Blair A, Stewart PA, Hoover RN (1990) Mortality from lung cancer among workers employed in formaldehyde industries. Am J Ind Med 17(6):683-699

47. Hauptmann M, Lubin JH, Stewart PA, Hayes RB, Blair A (2003) Mortality from lymphohematopoietic malignancies among workers in formaldehyde industries. J Natl Cancer Inst 95(21):1615-1623

48. Coggon D, Harris EC, Poole J, Palmer KT (2003) Extended follow-up of a cohort of british chemical workers exposed to formaldehyde. J Natl Cancer Inst 95(21):1608-1615

49. Acheson ED, Barnes HR, Gardner MJ, Osmond C, Pannett B, Taylor CP (1984) Formaldehyde in the British chemical industry. An occupational cohort study. Lancet 1(8377):611-616

50. Gardner MJ, Pannett B, Winter PD, Cruddas AM (1993) A cohort study of workers exposed to formaldehyde in the British chemical industry: an update. Br J Ind Med 50(9):827-834

51. Stayner L, Smith AB, Reeve G et al (1985) Proportionate mortality study of workers in the garment industry exposed to formaldehyde. Am J Ind Med 7(3):229-240

52. Stayner LT, Elliott L, Blade L, Keenlyside R, Halperin W (1988) A retrospective cohort mortality study of workers exposed to formaldehyde in the garment industry. Am J Ind Med 13(6):667-681

53. Pinkerton LE, Hein MJ, Stayner LT (2004) Mortality among a cohort of garment workers exposed to formaldehyde: an update. Occup Environ Med 61(3):193-200

54. Hauptmann M, Stewart PA, Lubin JH et al (2009) Mortality from lymphohematopoietic malignancies and brain cancer among embalmers exposed to formaldehyde. J Natl Cancer Inst 101(24):1696-1708

55. Walrath J, Fraumeni JF Jr (1983) Mortality patterns among embalmers. Int J Cancer 31(4):407-411

56. Hayes RB, Blair A, Stewart PA, Herrick RF, Mahar H (1990) Mortality of U.S. embalmers and funeral directors. Am J Ind Med 18(6):641-652

57. Levine RJ, Andjelkovich DA, Shaw LK (1984) The mortality of Ontario undertakers and a review of formaldehyde-related mortality studies. J Occup Med 26(10):740-746

58. Hall A, Harrington JM, Aw TC (1991) Mortality study of British pathologists. Am J Ind Med 20(1):83-89
59. Stroup NE, Blair A, Erikson GE (1986) Brain cancer and other causes of death in anatomists. J Natl Cancer Inst 77(6): $1217-1224$

60. Matanoski G (1989) Risk of pathologists exposed to formaldehyde. DHHS Grant No. 5 RO1 OHO1511-03 ed. John Hopkins University; Department of Epidemiology, School of Hygiene and Public Health

61. Robinson CF, Fowler D, Brown DP, Lemen RA (1987) Plywood mill workers' mortality patterns 1945, 1977 (Revised). NTIS $\mathrm{NIOSH}$

62. Partanen T, Kauppinen T, Luukkonen R, Hakulinen T, Pukkala E (1993) Malignant lymphomas and leukemias, and exposures in the wood industry: an industry-based case-referent study. Int Arch Occup Environ Health 64(8):593-596

63. Stellman SD, Demers PA, Colin D, Boffetta P (1998) Cancer mortality and wood dust exposure among participants in the American Cancer Society Cancer Prevention Study-II (CPS-II). Am J Ind Med 34(3):229-237

64. Fayerweather WE, Pell S, Bender JR (1983) Case-control study of cancer deaths in DuPont workers with potential exposure to formaldehyde. In: Clary JJ, Gibson JE, Waritz RS (eds) Formaldehyde: toxicology, epidemiology, mechanisms. Marcel Dekker, New York, pp 47-125

65. Bertazzi PA, Pesatori AC, Radice L, Zocchetti C, Vai T (1986) Exposure to formaldehyde and cancer mortality in a cohort of workers producing resins. Scand J Work Environ Health 12(5): 461-468

66. Ott MG, Teta MJ, Greenberg HL (1989) Lymphatic and hematopoietic tissue cancer in a chemical manufacturing environment. Am J Ind Med 16(6):631-643

67. Dell L, Teta MJ (1995) Mortality among workers at a plastics manufacturing and research and development facility: 1946-1988. Am J Ind Med 28(3):373-384

68. Cole P, Adami HO, Trichopoulos D, Mandel J (2010) Formaldehyde and lymphohematopoietic cancers: a review of two recent studies. Regul Toxicol Pharmacol 58(2):161-166

69. Rothman KJ, Boice JD (1979) Epidemiologic analysis with a programmable calculator. NIH Publication No. 79-1649. U.S. Department of Health, Education, and Welfare, Public Health Service, National Institutes of Health, Washington, DC

70. Blair A, Zheng T, Linos A, Stewart PA, Zhang YW, Cantor KP (2001) Occupation and leukemia: a population-based case-control study in Iowa and Minnesota. Am J Ind Med 40(1):3-14

71. Hansen J, Olsen JH (1995) Formaldehyde and cancer morbidity among male employees in Denmark. Cancer Causes Control 6(4): 354-360

72. Wang R, Zhang Y, Lan Q et al (2009) Occupational exposure to solvents and risk of non-Hodgkin lymphoma in Connecticut women. Am J Epidemiol 169(2):176-185

73. Stewart PA, Blair A, Cubit D et al (1986) Estimating historical exposures to formaldehyde in a retrospective mortality study. Appl Ind Hyg 1(1):34-41

74. Rhomberg LR, Bailey LA, Goodman JE, Hamade AK, Mayfield D (2011) Is exposure to formaldehyde in air causally associated with leukemia? A hypothesis-based weight-of-evidence analysis. Crit Rev Toxicol 41(7):555-621

75. Zhang L, Tang X, Rothman N et al (2010) Occupational exposure to formaldehyde, hematotoxicity, and leukemia-specific chromosome changes in cultured myeloid progenitor cells. Cancer Epidemiol Biomarkers Prev 19(1):80-88

76. Kuo H, Jian G, Chen C, Liu C, Lai J (1997) White blood cell count as an indicator of formaldehyde exposure. Bull Environ Contam Toxicol 59(2):261-267

77. Tang X, Bai Y, Duong A, Smith MT, Li L, Zhang L (2009) Formaldehyde in China: production, consumption, exposure levels, and health effects. Environ Int 35(8):1210-1224 
78. Zhang L, Freeman LE, Nakamura J et al (2010) Formaldehyde and leukemia: epidemiology, potential mechanisms, and implications for risk assessment. Environ Mol Mutagen 51(3):181-191

79. Arumanayagam M, Lam YM, Swaminathan R, Donnan SP, Hom BL (1987) Blood cell values in healthy Hong Kong Chinese adults. Clin Lab Haematol 9(3):263-269

80. Chng WJ, Tan GB, Kuperan P (2004) Establishment of adult peripheral blood lymphocyte subset reference range for an Asian population by single-platform flow cytometry: influence of age, sex, and race and comparison with other published studies. Clin Diagn Lab Immunol 11(1):168-173

81. Kam KM, Leung WL, Kwok MY, Hung MY, Lee SS, Mak WP (1996) Lymphocyte subpopulation reference ranges for monitoring human immunodeficiency virus-infected Chinese adults. Clin Diagn Lab Immunol 3(3):326-330

82. Grant J (1969) Haematological indices in healthy Chinese (a survey of 3,983 students in Hong Kong). Singapore Med J 10(3): 211-213

83. Lu K, Collins LB, Ru H, Bermudez E, Swenberg JA (2010) Distribution of DNA adducts caused by inhaled formaldehyde is consistent with induction of nasal carcinoma but not leukemia. Toxicol Sci 116(2):441-451

84. Moeller BC, Lu K, Doyle-Eisele M, McDonald J, Gigliotti A, Swenberg JA (2011) Determination of N2-hydroxymethyl-dG adducts in the nasal epithelium and bone marrow of nonhuman primates following 13CD2-formaldehyde inhalation exposure. Chem Res Toxicol 24(2):162-164

85. Swenberg JA, Lu K, Moeller BC et al (2011) Endogenous versus exogenous DNA adducts: their role in carcinogenesis, epidemiology, and risk assessment. Toxicol Sci 120(Suppl 1):S130S145

86. Liebling T, Rosenman KD, Pastides H, Griffith RG, Lemeshow $S$ (1984) Cancer mortality among workers exposed to formaldehyde. Am J Ind Med 5(6):423-428

87. Hagmar L, Bellander T, Englander V, Ranstam J, Attewell R, Skerfving S (1986) Mortality and cancer morbidity among workers in a chemical factory. Scand J Work Environ Health 12(6):545-551

88. Logue JN, Barrick MK, Jessup GL Jr (1986) Mortality of radiologists and pathologists in the radiation registry of physicians. J Occup Med 28(2):91-99

89. Andjelkovich DA, Janszen DB, Brown MH, Richardson RB, Miller FJ (1995) Mortality of iron foundry workers: IV. Analysis of a subcohort exposed to formaldehyde. J Occup Environ Med 37(7):826-837

90. Rapiti E, Fantini F, Dell'Orco V et al (1997) Cancer mortality among chemical workers in an Italian plant. Eur J Epidemiol 13(3):281-285
91. Ambroise D, Moulin JJ, Squinazi F, Protois JC, Fontana JM, Wild P (2005) Cancer mortality among municipal pest-control workers. Int Arch Occup Environ Health 78(5):387-393

92. Linos A, Kyle RA, O'Fallon WM, Kurland LT (1980) A casecontrol study of occupational exposures and leukaemia. Int J Epidemiol 9(2):131-135

93. Boffetta P, Stellman SD, Garfinkel L (1989) A case-control study of multiple myeloma nested in the American Cancer Society prospective study. Int J Cancer 43(4):554-559

94. Gerin M, Siemiatycki J, Nadon L, Dewar R, Krewski D (1989) Cancer risks due to occupational exposure to formaldehyde: results of a multi-site case-control study in Montreal. Int $\mathrm{J}$ Cancer 44(1):53-58

95. Heineman EF, Olsen JH, Pottern LM, Gomez M, Raffn E, Blair A (1992) Occupational risk factors for multiple myeloma among Danish men. Cancer Causes Control 3(6):555-568

96. Pottern LM, Heineman EF, Olsen JH, Raffn E, Blair A (1992) Multiple myeloma among Danish women: employment history and workplace exposures. Cancer Causes Control 3(5):427-432

97. Blair A, Linos A, Stewart PA et al (1993) Evaluation of risks for non-Hodgkin's lymphoma by occupation and industry exposures from a case-control study. Am J Ind Med 23(2):301-312

98. West RR, Stafford DA, Farrow A, Jacobs A (1995) Occupational and environmental exposures and myelodysplasia: a casecontrol study. Leuk Res 19(2):127-139

99. Band PR, Le ND, Fang R et al (1997) Cohort mortality study of pulp and paper mill workers in British Columbia, Canada. Am J Epidemiol 146(2):186-194

100. Tatham L, Tolbert P, Kjeldsberg C (1997) Occupational risk factors for subgroups of non-Hodgkin's lymphoma. Epidemiology 8(5):551-558

101. Nisse C, Haguenoer JM, Grandbastien B et al (2001) Occupational and environmental risk factors of the myelodysplastic syndromes in the North of France. Br J Haematol 112(4): 927-935

102. Tranah GJ, Holly EA, Bracci PM (2009) Solvent exposure and non-Hodgkin lymphoma: no risk in a population-based study in the San Francisco Bay Area. Cancer Epidemiol Biomarkers Prev 18(11):3130-3132

103. Wong O, Harris F, Armstrong TW, Hua F (2010) A hospitalbased case-control study of non-Hodgkin lymphoid neoplasms in Shanghai: analysis of environmental and occupational risk factors by subtypes of the WHO classification. Chem Biol Interact 184(1-2):129-146 